\title{
Genetic and Pharmacological Analysis of Neurotransmitters Controlling Egg Laying in C. elegans
}

\author{
David Weinshenker, ${ }^{1}$ Gian Garriga, ${ }^{2}$ and James H. Thomas ${ }^{1}$ \\ 'Department of Genetics, University of Washington, Seattle, Washington 98195-7360 and 'Department of Cell and \\ Molecular Biology, University of California, Berkeley, California 94720
}

\begin{abstract}
We have investigated the neurotransmitters used to control egg-laying in $C$. elegans. Previous studies suggested that 5-HT released by the HSN motor neurons stimulates egg laying, and that tricyclic antidepressants potentiate egg laying by blocking reuptake of 5-HT by the HSN neurons. We report studies of the wild type and a mutant that lacks detectable 5-HT that suggest 5-HT is not required for egglaying. Furthermore, we find that $\mathrm{ACh}$ is required for egg laying in response to $5-\mathrm{HT}$, suggesting that 5- $\mathrm{HT}$ is not sufficient to activate egg laying. The dominant egl-2(n693) mutation, which causes animals to lay eggs in response to tricyclics but not 5-HT, also conflicts with the model for egg laying. Experiments in which the HSN neurons or 5-HT are removed from egl-2 animals indicate that the action of tricyclics cannot be explained by a block of 5-HT reuptake. We find that $D_{2}$ family dopamine antagonists can also induce egg laying in egl-2(n693) mutants, and that dopamine inhibits egg laying in the wild type. These results suggest that dominant egl-2 mutations activate an inhibitory dopaminergic pathway that can be blocked by tricyclics and $D_{2}$ antagonists. We also find that these drugs stimulate egg laying in mutants lacking 5-HT or the HSN neurons, consistent with a target on the egg-laying muscles. In contrast to tricyclics, fluoxetine and other selective 5-HT reuptake inhibitors appear to be specific for 5-HT reuptake in C. elegans egg laying.
\end{abstract}

[Key words: C. elegans, dopamine, egg laying, fluoxetine, genetics, HSN neurons, imipramine, pharmacology, 5-HT, tricyclic antidepressant]

Genetic analysis can test the validity in vivo of mechanisms of synaptic transmission and can identify genes that mediate synaptic transmission. Many of the ncurotransmitters found in mammals are also found in the genetic model organism Caenorhab-

\footnotetext{
Received Apr. 3, 1995; revised June 19, 1995; accepted June 21, 1995.

Many nematode strains were provided by the Caenorhahditis Genetics Center, which is funded by the NIH National Center for Research Resources (NCRR). Other strains were provided by the MRC in Cambridge, England and Jim Lewis of the University of Texas at San Antonio. We thank Carl Johnson for advice and unpublished data on egl-2 and Mark Hamblin for advice and providing pharmacological agents. We thank the Eli Lilly Co. and the University of Washington Medical Center for providing fluoxetine and other antidepressants. We thank Erik Jorgensen, Carol Trent, Mark Hamblin, David Reiner, and Elizabeth Malone for helpful discussions and critical reading of the manuscript, Bill Schafer for the tip on haloperidol, and a reviewer for suggesting significant improvements to the manuscript. This work was supported by U.S. Public Health Research Grants R01NS30187 and R01NS32057.

Correspondence should be addressed to James H. Thomas at the above address.

Copyright $(1995$ Society for Neuroscience $0270-6474 / 95 / 156975-11 \$ 05.00 / 0$
}

ditis elegans (Sulston, Dew, and Brenner, 1975; Horvitz et al., 1982; Rand and Russell, 1984; McIntire et al., 1993b). Several studies have investigated the role of neurotransmitters in controlling egg laying in C. elegans hermaphrodites (Horvitz et al., 1982; Trent et al., 1983; Desai et al., 1988; Schafer and Kenyon, 1995). The cells involved in egg laying have been precisely described. Eight uterine muscle cells and eight vulval muscle cells contract to push fertilized eggs through the vulva (Sulston and Horvitz, 1977). All 16 muscle cells are connected by gap junctions and appear to be coordinately regulated by the nervous system. The two bilaterally symmetric HSN neurons and the six VC neurons synapse with the egg-laying muscles, and some other neurons may indirectly regulate egg laying (White et al., 1976; White et al., 1986).

The current model for synaptic control of egg laying is that the HSN neurons release 5-HT, which acts directly on the egglaying muscles and causes their contraction. This model, shown in Figure 1, is based primarily on these observations: (1) the HSN neurons synapse with the egg-laying muscles (White et al., 1976, 1986); (2) killing the HSN neurons causes an egg-laying defective (Egl) phenotype, in which animals abnormally retain eggs (Desai et al., 1988); (3) animals lay eggs in response to exogenous 5-HT even in the absence of the HSN neurons (Trent et al., 1983); (4) the HSN neurons contain 5-HT (Desai et al., 1988); and (5) imipramine, a tricyclic antidepressant, induces egg laying and functioning HSN neurons are required for this response (Desai and Horvitz, 1989). Imipramine is hypothesized to induce egg laying by blocking reuptake of 5-HT released by the HSN neurons, resulting in increased 5-HT levels in the synaptic cleft (Briley, 1985; Desai and Horvitz, 1989). This model predicts that all Egl mutants that fail to lay eggs in response to 5-HT should also fail to respond to imipramine, a prediction that is met by all Egl mutants except egl-2(n693), which lays eggs in response to imipramine but not 5-HT (Trent et al., 1983). This result challenges either the validity of this model for egg laying or the mechanism by which imipramine acts.

Tricyclic antidepressants are used to treat a variety of human neurological disorders, but it is unclear whether their therapeutic action results from blocking 5-HT reuptake or from known nonserotonergic targets, including muscarinic, histaminergic, adrenergic (Fuller, 1987), and dopaminergic receptors (Austin et al., 1991; Smialowski, 1991). The functional significance of the molecular targets of such drugs can be studied genetically in $C$. elegans, though it remains to be tested how closely the action of tricyclics in nematodes parallels their action in humans.

\section{Materials and Methods}

General genetic methods. Methods for the culture and genetic analysis of C. elegans were as described by Brenner (1974). All strains were grown at $20^{\circ} \mathrm{C}$ and assayed at room temperature unless otherwise noted. 


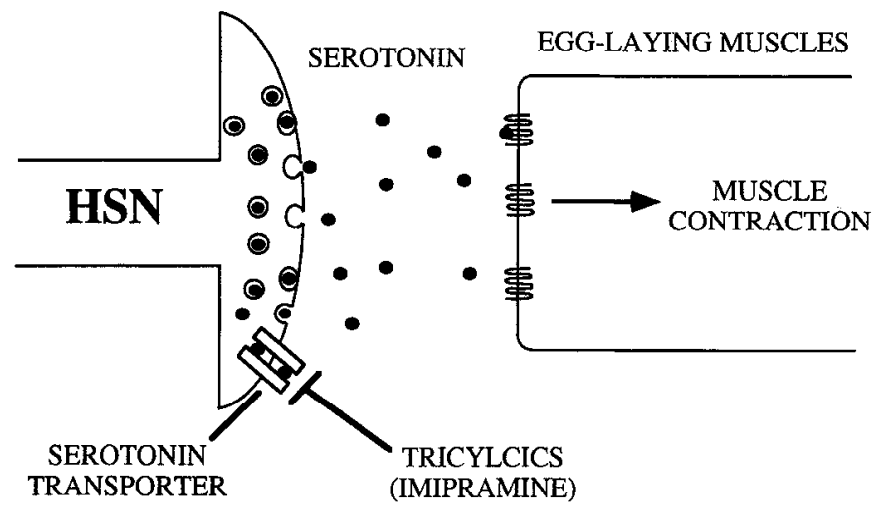

Figure 1. Schematic of standard model of egg laying in C. elegans. 5-HT-containing HSN neurons release 5-HT, which acts directly on the egg-laying muscles to cause contraction. Imipramine stimulates egg laying by blocking reuptake of 5-HT. Arrows represent a positive input; bars represent a negative input.

The following single and double mutant markers were used in strain constructions:

I.GIIT: $d p y-17(e 164)$ unc-32(e189), dpy-17(e164) unc-36(e251).

LGV: unc-76(e911), dpy-11(e224) unc-76(e911), egl-2(n693sd) unc76(e911), egl-1(n986dm) sqt-3(sc63sd,ts).

Behavioral assays were performed on the following strains: $\mathrm{CB} 193$ unc-29(e193) I, CB264 unc-38(e264) I, CB306 unc-50(e306) III, CB883 unc-74(e883) I, CB933 unc-17(e245) IV, CB 1072 unc-29(el072am) I, CB1141 cat-4(el14l) V, JT5248 unc-75(e950) I, JT5302 egl-2(n693sd) $V$, JT6726 egl-2(n693sd) egl-I (n487dm) V, JT7085 cat-4(e1141) eglI(n487dm) V, JT7086 cha-1(pl152) IV; cat-4(el141) V, JT7169 egl$I(n 986 d m) V$, J17198 egl-2(n693sd) cat-4(e1141) V, J17228 basI(ad446) III; egl-1(n487dm) V, JT7257 bas-1(ad446) III; egl-2(n693sd) $V, \mathrm{JT7258}$ cat-4(el141) egl-l(n986dm) $V$, JT7306 egl-1(n693sd) V, JT7589 lin-39(n709ts) III; egl-2(n693sd) V, MT1082 egl-l(n487dm) V, MT1514 lin-39(n709ts) III, MT7988 bas-1(ad446) III, PR1152 cha$l(p l 1.52) I V$, PR 1170 unc- $17(p 300) I V$, RM48 cha-l(pll86ts) IV, 77.20 unc-38(x20) I, ZZ37 unc-63(x37) I, ZZ411 unc-38(x411) I, ZZ415 unc$29(x 415) 1$

Indirect immunofluorescence histochemistry and microscopy. Indirect immunofluorescence histochemistry was used to stain animals using a modification of the procedure described by Garriga et al. (1993). Animals were fixed for $24 \mathrm{hr}$ at $4^{\circ} \mathrm{C}$ in a solution containing PBS $(10.4$ $\mathrm{mM} \mathrm{Na}_{2} \mathrm{HPO}_{4}, 1.8 \mathrm{mM} \mathrm{KH}_{2} \mathrm{PO}_{4}, 137 \mathrm{~mm} \mathrm{NaCl}, 4.4 \mathrm{mM} \mathrm{KCl}, \mathrm{pH} 7.2$ ) and $4 \%$ paraformaldehyde fixative. After being washed three to four times in PBS, the worms were rocked gently overnight at $37^{\circ} \mathrm{C}$ in a solution of $5 \% \beta$-mercaptoethanol, $1 \%$ Triton $\mathrm{X}-100$ in $0.125 \mathrm{M}$ Tris $\mathrm{HCl} \mathrm{pH} \mathrm{6.9.} \mathrm{The} \mathrm{worms} \mathrm{were} \mathrm{washed} \mathrm{three} \mathrm{more} \mathrm{times} \mathrm{in} \mathrm{PBS,} \mathrm{and}$ $20-30 \mathrm{ml}$ of worms were rocked for $1 \mathrm{hr}$ in $0.4 \mathrm{ml}$ of $100 \mathrm{~mm}$ Tris $\mathrm{HCl}$ pH 7.5, $1 \mathrm{mM} \mathrm{CaCl}_{2}$ and $1000 \mathrm{U} / \mathrm{ml}$ collagenase type IV (Sigma, St. Louis, MO). The worms were washed three times with PBS, one time with a solution containing $1.0 \%$ BSA, $1.0 \%$ Triton X-100 and $1 \mathrm{~mm}$ sodium azide in PBS, and incubated overnight at room temperature in $20 \mu \mathrm{l}$ of a solution containing $1.0 \%$ rabbit anti-5-HT antiserum (provided by $J$. Steinbusch, Free University, Amsterdam, The Netherlands), $0.1 \% \mathrm{MH} 27$ (provided by $\mathrm{R}$. Waterston, Washington University, St. Louis, MO), $1.0 \%$ BSA, $1.0 \%$ Triton $\mathrm{X}-100$, and $1 \mathrm{~mm}$ sodium azide in PBS. (MH27 is a mouse monoclonal antibody that recognizes an antigen present in C. elegans desmosomes (Waterston, 1988) and was used to show that animals could be stained with antibodies.) The worms were then washed three times with a solution containing $1.0 \%$ BSA, $1.0 \%$ Triton X-100 and $1 \mathrm{~mm}$ sodium azide in PBS and incubated overnight at room temperature in $20 \mu \mathrm{l}$ of a solution containing $1.0 \%$ FITCconjugated goat anti-rabbit antiserum (Cappel Inc., West Chester, PA), $0.3 \%$ indocarbocyanine (Cy3)-conjugated donkey anti-mouse antiserum (Jackson Immunoresearch Laboratories Inc., West Grove, PA), 1.0\% BSA, $1.0 \%$ Triton X-100, and $1 \mathrm{~mm}$ sodium azide in PBS. The worms were then washed three times in a solution containing $1.0 \%$ BSA, $1.0 \%$ Triton X-100, and $1 \mathrm{~mm}$ sodium azide in PBS; $5 \mu \mathrm{l}$ of stained worms were mixed with $5 \mu \mathrm{l}$ of $1 \mathrm{mg} / \mathrm{ml} p$-phenylenediamine in $10 \% \mathrm{PBS} \mathrm{pH}$ 8.0 and $90 \%$ glycerol and viewed by standard fluorescence microscopy. Anti-5-HT and MH27 staining was detected by illumination with a mer- cury vapor lamp using a fluorescein filter (Zeiss 487910) for 5-HT and a rhodamine filter (Zeiss 487915) for MH27. Stained worms were photographed with Ektachrome 160T slide film (Kodak), the slides were scanned using a Nikon Coolscan color slide scanner, and images were prepared with ADOBE PHOTOSHOP software.

Construction of double mutants containing cat-4(e1141) or bas1(ad446). In general, mutations were tracked in crosses on the basis of their own visible phenotypes. However, cat-4(e1141) and bas-1(ad446) do not have obvious phenotypes, so flanking markers were used in trans to track them in constructing double mutants. An example is the construction of the double mutant between egl-2(n693) and cat-4(e1141), genes that are loosely linked on chromosome V. dpy-11 unc-76 I+ males were mated to egl-2 hermaphrodites. $d p y-11$ and unc-76 map close to the left and right of cat-4, respectively. Males from this cross, half of them being of the genotype egl-2/dpy-11 unc-76, were mated to cat-4 hermaphrodites. Many L4 hermaphrodite progeny were picked singly to plates. Plates that segregated Egl Dpy Unc progeny were inferred to be from parents of the genotype egl-2 dpy-11 unc-76/cat-4, arising from a recombinant chromosome from the male. Egl non Dpy Unc hermaphrodites were picked singly to plates, and parents segregating all Fgl and no Dpy Unc progeny were inferred to be the egl-2 cat-4 double mutant. A different method was used for the cat-4(e1141) egl- $1(n 986 \mathrm{dm})$ double mutant because the genes are tightly linked. cat -4 males were mated to a $s q t-3(s c 63 s d)$ egl-1 $(n 986 d m)$ strain. Cross progeny were picked on the basis of the Rol phenotype of $s q t-3$ heterozygotes. Progeny of these sqt-3 egl-1/cat-4 animals were screened for Egl non Rol recombinants. The order of these genes is cat-4-sqt-3-egl-1, so these recombinants were inferred to be of the genotype cat-4 egl-1/ + . Egl animals were picked individually to plates, and parents segregating all Egl progeny were inferred to be cat-4 egl-1 double mutants. All double mutant strains containing cat-4 or bas-1 were checked for the presence of cat 4 or bas- 1 by immunocytochemistry for reduced 5-HT staining. To ensure that both mutant genes were present in bas1; cat-4, the double mutant was deconstructed using the balancers $d p y$ 11 unc- 76 for cat -4 and $d p y-17 u n c-36$ for bas-1, and the resulting bas- 1 and cat-4 single mutant strains were tested individually for 5-HT deficiency.

Construction of egl-2(n693sd) egl-1(n487dm). egl-2(n693sd) is semidominant and masks the dominant egl-1 Egl phenotype. To construct an egl-2 egl-1 double mutant, $u n c-76$ was used as a trans marker to track $e g l-l$, and the constipated (Con) phenotype (Thomas, 1990) was used to track egl-2. egl-1/+ males were mated to egl-2 unc-76 hermaphrodites. Hermaphrodite cross progeny were picked individually to plates, and parents segregating all Egl progeny were inferred to be of the genotype egl-2 unc-76/egl-1. Con non Unc animals were picked individually to plates, and parents segregating all Con non Unc progeny were inferred to be $e g l-2$ egl-1. The egl-1 Egl phenotype is caused by the absence of the HSN neurons (Trent et al., 1983), while the HSN ncurons in egl-2 animals are intact (data not shown). The presence of egl-1 in this strain was confirmed by the absence of the HSN neurons in $12 \mathrm{~L} 4$ animals (Sulston and Horvitz, 1977).

Construction of the lin-39(n709ts); egl-2(n693) double mutant. dpy17 unc-32 were used as trans markers to track lin-39(n709ts), while $e g l-2(n 693 s d)$ was tracked by the Con phenotype. lin-39(n709ts) causes incompletely penetrant vulval defects in addition to causing death of the VC neurons (Ellis, 1985; Clark et al., 1993; Salser et al., 1993). Therefore, if loss of the VC neurons indeed rescued the Egl phenotype of $e g l-2(n 693)$, the rescue could be variably masked by vulval lineage defects, which can cause an $\mathrm{Egl}$ phenotype. To minimize this problem, we looked for rescue of individual animals in populations of this strain that were grown at $25^{\circ}$ and shifted to $20^{\circ}$ at each larval stage. The approximate temperature-sensitive period in $\operatorname{lin}-39(n 709 t s)$ for vulval development is the L3 stage, while the temperature-sensitive period for cell death of the VC neurons is earlier (Ellis, 1985). No rescue of the Egl defect was found under any conditions.

Egg-laying assays in microtiter wells. Egg-laying assays were performed on individual animals in microtiter wells containing $50 \mu \mathrm{l}$ of solution as described (Trent et al., 1983). After a 90 min incubation period, eggs were counted and results were expressed as the mean number of eggs laid per animal. Animals were grown at $20^{\circ}$ and tested at room temperature, and hermaphrodites with one full row of eggs in their gonads (10-15 eggs) were used in all assays. cha-1(p1186ts) animals were grown at $20^{\circ}$ and assayed at $20^{\circ}$ (permissive temperature assays), or were grown at $20^{\circ}$, shifted to $25^{\circ}$ for two hours, and assayed at $25^{\circ}$ (restrictive temperature assays). 
anti-serotonin
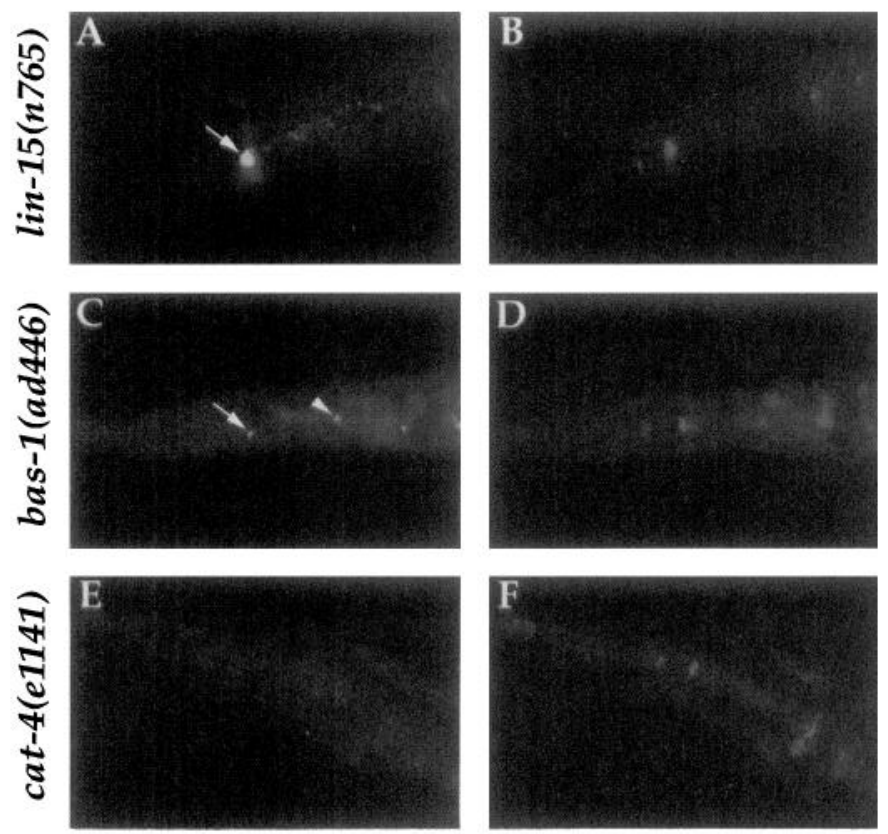

Figure 2. 5-HT levels in bas-1 and cat-4 mutants. Fluorescence photomicrographs of adult hermaphrodites showing anti-5-HT $(A, C, E)$ and MH27 $(B, D, F)$ staining. Each photomicrograph shows the anterior end of an adult hermaphrodite; anterior is to the left. In this experiment him5(e1490); $\operatorname{lin}-15(n 765)$ animals were mixed with either bas-1 or cat -4 animals, and the mixed populations were fixed, permeabilized, and stained with an anti-5-HT antiserum $(A, C, E)$ and MH27 $(B, D, F)$. MH27 is a mouse monoclonal antibody that recognizes an antigen present in C. elegans desmosomes (Waterston, 1988) and was used as a control to show that animals that failed to stain with the anti-5-HT antiserum could be stained with antibodies. him-5(e1490); lin-15(n765) animals were used as a control to show that the anti-5-HT antiserum could recognize serotonergic neurons in a specific preparation. lin-15 hermaphrodites display ectopic protrusions along their ventral surface that consist of vulval cells (Ferguson and Horvitz, 1985). In addition, the him-5 mutation causes a high incidence of males; bas-1 and cat-4 mutants produce very few males. Thus, in the mixed populations of stained animals, all hermaphrodites displaying ectopic ventral protrusions and nearly all males were of the genotype him-5; lin-15, and all hermaphrodites lacking ectopic ventral protrusions were of the genotype bas-1 or cat-4. A and B, A him-5; lin-15 hermaphrodite double stained with an anti-5-HT antiserum and MH27. This animal displayed ectopic ventral protrusions (not shown) and was from an experiment in which him-5; lin-15 and bas-1 animals were mixed. The arrow indicates the cell body of one of the two serotonergic NSM neurons (NSML). An NSML process, which extends from the cell body to the right, is also visible in this photomicrograph. The NSM cell bodies and processes stained intensely in all him-5; lin- 15 animals. $C$ and $D$, A bas- 1 hermaphrodite double stained with an anti-5-HT antiserum and MH27. The arrow indicates the cell body of one of the two serotonergic NSM neurons (NSML). The NSM cell bodies of bas- 1 hermaphrodites stained less intensely than the NSM cell bodies of him-5; lin-15 hermaphrodites from the same preparation (e.g., $A$ ). Moreover, we could not detect the NSM processes of bas- $I$ animals in this preparation. The arrowhead indicates the serotonergic ADFL cell body. The ADF cell body is out of the plane of focus in A. The 5-HT levels in all serotonergic neurons of bas- 1 animals varied among preparations, but were always reduced compared to 5-HT levels in wild-type animals. These observations contrast with those of Loer and Kenyon (1993), who failed to detect 5-HT immunocytochemically in bas- 1 animals. $E$ and $F$, A cat-4 hermaphrodite double stained with an anti-5-HT antiserum and $\mathrm{MH} 27$. Although this animal stained with $\mathrm{MH} 27$, no 5-HT staining is detectable. The him-5; lin-15 animals from this preparation stained normally with the anti-5-HT antiserum (not shown). Consistent with previous observations (Desai et al., 1988; Loer and Kenyon, 1993), we have never detected 5-HT immunocytochemically in cat-4 animals.

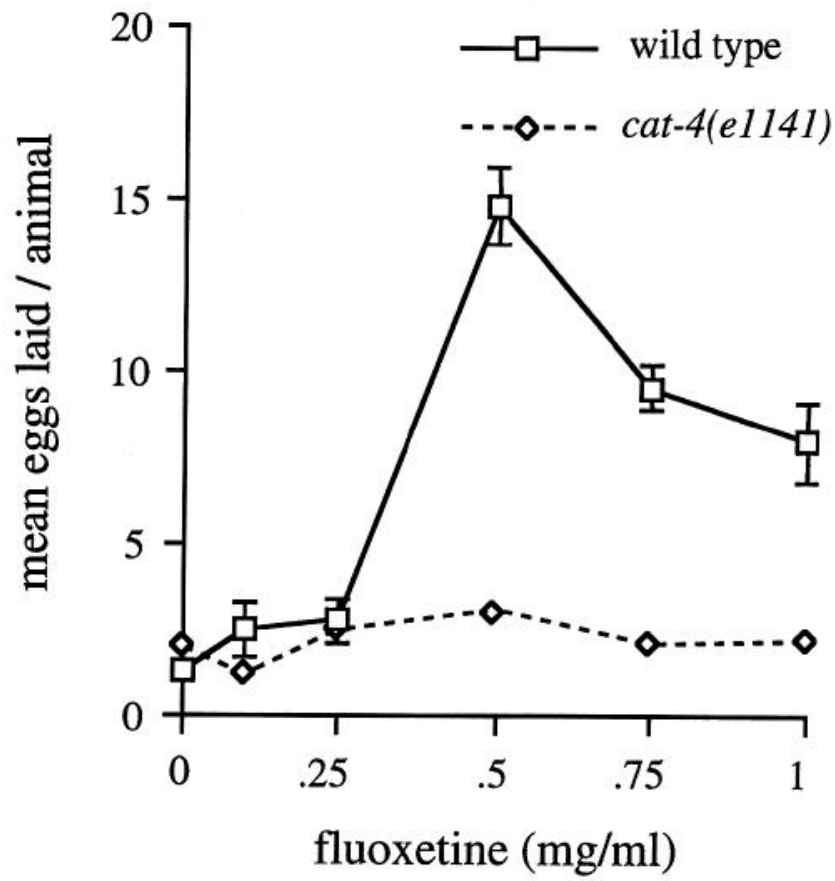

Figure 3. Dose response to fluoxetine of wild type and cat-4(e1141) egg laying. See Materials and Methods and the Table 2 caption for description of egg-laying assays. At least 12 animals were assayed for each data point. Error bars represent the SEM. Some error bars appear to be missing because they are too small to extend beyond the graph symbol. No cat-4 responses were significantly different from the no drug control.

5-HT, levamisole, oxotremorine, 5-HT antagonists, chlorpromazine, and tricyclic antidepressants were dissolved in M9 buffer (Brenner, 1974), and M9 was used as the no drug control. Dopamine and dopamine antagonists were dissolved in distilled water, and distilled water was used as the no drug control, because M9 buffer inhibits the action of these drugs in C. elegans (William Schafer, personal communication; our data not shown). Because of difficulties encountered in solubilizing the drugs, tricyclic antidepressants, 5-HT antagonists, and dopamine antagonists were vortexed and sonicated, and then incubated on rollers at $37^{\circ} \mathrm{C}$ overnight before use. All other drugs were subjected to vortexing only. Drug concentrations were optimized using dose-response curves of wild type and egl-1(n487dm) animals (data not shown). High drug doses were necessary due to the general impermeability of the $C$. elegans cuticle (e.g., Lewis et al., 1980).

The Wilcoxon/Mann-Whitney test, a nonparametric statistical test, was used to test significance of drug responses. $P$ values shown represent the difference of the drug response compared to the no drug control for each strain tested. Both the standard deviation and the standard error of the mean were calculated for each response, and the standard error of the mean is shown. In many cases, the standard deviation was equal to or greater than the mean, reflecting the high variability among individual animals tested (Trent et al., 1983). In order to account for this variability, at least 30 animals were assayed for each test unless otherwise noted. All statistical calculations were performed using $\mathbb{N}$ STAT 2.01 for the Macintosh.

Defecation assays. Defecation was scored as described by Thomas (1990). For drug tests, $0.7 \mathrm{ml}$ of $10 \mathrm{mg} / \mathrm{ml}(5-\mathrm{HT})$ or $0.75 \mathrm{mg} / \mathrm{ml}$ (tricyclic antidepressants, dopamine antagonists, 5-HT antagonists, phentolamine) of drug dissolved in distilled water was poured onto NG agar plates with a lawn of $E$. coli. After the plates dried for $45 \mathrm{~min}$, worms were picked onto the plates, incubated for $45 \mathrm{~min}$ at room temperature, and then assayed for defecation. For dopamine tests, $1.4 \%$ agar plates containing only $6 \mathrm{mg} / \mathrm{ml}$ dopamine were made and dried overnight. For octopamine tests, $1.4 \%$ agar plates containing $20 \mathrm{mg} / \mathrm{ml}$ octopamine were made and dried overnight. Several animals were picked onto the plates, incubated for $45 \mathrm{~min}$ at room temperature, and directly assayed for defecation. For each test, two observations were made. First, the plate was screened qualitatively for constipated animals. Second, at least 
Table 1. Pharmacology of mutants lacking HSN motor neurons and mutants with reduced 5-HT levels

\begin{tabular}{|c|c|c|c|c|c|c|}
\hline Genotype & & No drug & Imipramine & Clomipramine & Chlorpromazine & Fluoxetine \\
\hline \multirow[t]{3}{*}{ Wild type } & Mean & $1.24 \pm 0.18$ & $10.01 \pm 0.33$ & $8.60 \pm 1.07$ & $8.64 \pm 0.98$ & $7.94 \pm 1.16$ \\
\hline & $N$ & 161 & 162 & 30 & 36 & 18 \\
\hline & $P$ & 一 & $<0.0001$ & $<0.0001$ & $<0.0001$ & $<0.0001$ \\
\hline \multirow[t]{3}{*}{$\operatorname{cat}-4(e 1141)$} & Mean & $1.91 \pm 0.41$ & $7.50 \pm 0.79$ & $0.11 \pm 0.07$ & $1.22 \pm 0.26$ & $2.00 \pm 0.78$ \\
\hline & $N$ & 65 & 36 & 36 & 36 & 12 \\
\hline & $P$ & - & $<0.0001$ & 0.02 & 0.76 & 0.31 \\
\hline \multirow[t]{3}{*}{$\operatorname{egl}-\operatorname{l}(n 487)$} & Mean & $0.14 \pm 0.12$ & $2.13 \pm 0.52$ & $3.60 \pm 0.46$ & $5.19 \pm 0.70$ & $0.71 \pm 0.4$ \\
\hline & $N$ & 35 & 69 & 72 & 36 & 31 \\
\hline & $P$ & - & 0.03 & $<0.0001$ & $<0.0001$ & 0.75 \\
\hline \multirow[t]{3}{*}{ egl-1(n986) } & Mean & 0 & $1.31 \pm 0.38$ & $2.22 \pm 0.52$ & $4.44 \pm 0.71$ & $0.03 \pm 0.03$ \\
\hline & $N$ & 36 & 80 & 36 & 36 & 30 \\
\hline & $P$ & & 0.03 & 0.0003 & $<0.0001$ & 0.98 \\
\hline \multirow[t]{3}{*}{ cat-4(el14l) egl-1(n986) } & Mean & $0.13 \pm 0.07$ & $2.83 \pm 0.63$ & $0.86 \pm 0.25$ & $1.28 \pm 0.29$ & ND \\
\hline & $N$ & 71 & 36 & 36 & 36 & \\
\hline & $P$ & - & $<0.0001$ & 0.014 & $<0.0001$ & \\
\hline \multirow{3}{*}{$\begin{array}{l}\text { cat-4(e1141) egl-l(n986) } \\
\text { at lower drug concentration }\end{array}$} & Mean & $0.13 \pm 0.07$ & ND & $2.75 \pm 0.53^{a}$ & $3.06 \pm 0.58^{b}$ & ND \\
\hline & $N$ & 71 & & 36 & 36 & \\
\hline & $P$ & - & & $<0.0001$ & $<0.0001$ & \\
\hline
\end{tabular}

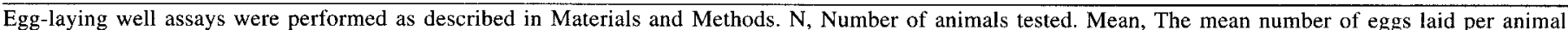

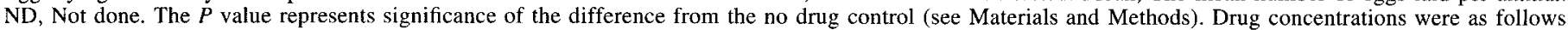

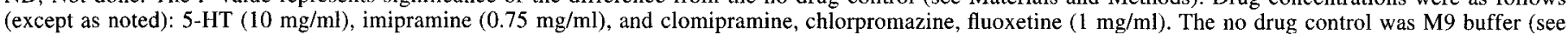
Materials and Methods). All of these strains lay eggs normally in response to 5-HT (Desai et al., 1988, and data not shown).

a $0.75 \mathrm{mg} / \mathrm{ml}$ clomipramine.

${ }^{b} 0.50 \mathrm{mg} / \mathrm{ml}$ chlorpromazine.

threc randomly sclectcd individual animals werc dircetly obscrved for $10 \mathrm{~min}$ each. Results of this quantitative assay were recorded as \%EMC (Enteric Muscle Contraction), which is calculated by dividing the number of enteric muscle contractions observed by the total number of defecation motor program (DMP) initiations. DMPs were scored by the presence of the posterior body wall muscle contraction (pBoc) (Croll, 1975; Thomas, 1990). The Wilcoxon/Mann-Whitney test was used to test significance of \%EMC between strains and between different drugs for the same strain.

Egg-laying plate assays. Drug plates were prepared as in the defecation assays (see above). At least 10 adult worms of each genotype tested were picked onto plates and incubated at room temperature for $45 \mathrm{~min}$. The plates were then screened qualitatively for laid eggs.

\section{Results}

Evidence that 5-HT from the HSN neurons stimulates egg laying and that 5-HT-induced egg laying is ACh-dependent

If 5-HT were the sole excitatory transmitter for the egg-laying muscles, then mutants that lack 5-HT should be egg-laying defective (Egl). Mutants with reduced 5-HT levels have been identified (Desai et al., 1988; Loer and Kenyon, 1993). In particular, the cat-4(e1141) mutant lacks immunocytochemically detectable 5-HT (Fig. 2), but lays eggs at a normal rate, suggesting that 5-HT is not required for egg laying. It remained possible that cat-4(e114I) contains residual 5-HT that is not detectable by immunocytochemistry but is sufficient for normal egg laying (Desai et al., 1988). We have made two observations that argue against this possibility. First, neither the bas-1(ad446) mutant, which also has reduced 5-HT levels (Fig. 2; Loer and Kenyon, 1993), nor the bas-1; cat-4 double mutant have an Egl phenotype (data not shown). Second, residual 5-HT in cat-4 in amounts sufficient to permit normal egg laying should be potentiated by 5 -HT reuptake inhibitors. We found that the sclective 5-HT reuptake inhibitor (SSRI) fluoxetine induces egg laying in the wild type, and that this induction is completely abolished by the cat-4 mutation (Fig. 3, Table 1). Since cat-4(e1141) also causes reduced levels of dopamine, a negative regulator of egg laying (Schafer and Kenyon, 1995), it remained possible that the loss of inhibitory dopamine compensates for the loss of excitatory 5-HT. If this were the case, and 5-HT were the sole excitatory transmitter from the HSN neurons, then the reduction of dopamine in cat-4(e1141) should compensate for a lack of the HSN neurons. In order to test this prediction, we constructed cat-4(e1141) as a double mutant with egl-1(n986), a mutation that causes the HSN neurons to undergo programmed cell death (Desai et al., 1988). Since cat-4(e1141) does not cause an obvious phenotype, its presence in the double mutant was confirmed by immunocytochemistry (see Materials and Methods). cat-4(e1141) did not suppress the Egl phenotype of egl-1 (not shown), nor did the double mutant lay any more eggs than the egl-1 single mutants in the no drug control (Table 1).

Taken together, these results suggest that 5 -HT is not required for egg laying. In contrast, animals lacking the serotonergic HSN neurons are severely Egl (Desai et al., 1988), implying that there is another neurotransmitter from the HSN neurons that is required for normal egg laying. One candidate transmitter is acetylcholine. Both levamisole and oxotremorine, nicotinic and muscarinic ACh agonists, respectively, are strong stimulators of egg laying in the wild type (Table 2; Trent et al., 1983). However, ACh may not be required for egg laying, since levamisoleresistant mutants (Lewis et al., 1980) and ChAT mutants (Rand and Russell, 1984) are not egg-laying defective. We also found that egg laying in response to ACh agonists levamisole and oxotremorine is dependent on the HSN neurons (Table 2). We hypothesized that ACh and 5-HT act in parallel on the egg-laying muscles, and tested this by assaying the ability of mutants defective in ACh transmission to lay eggs in response to exogenous 5-HT (Table 3). All presynaptic ACh mutants tested, including several cha-1 (ChAT; Rand and Russell, 1984) and 


Table 2. Mutant egg laying in response to cholinergic agonists
\begin{tabular}{lllll} 
Genotype & & No drug & Levamisole & Oxotremorine \\
\hline Wild type & Mean & $1.24 \pm 0.18$ & $7.11 \pm 0.67$ & $5.17 \pm 0.69$ \\
& $N$ & 161 & 54 & 24 \\
& $P$ & - & $<0.0001$ & $<0.0001$ \\
egl-1(n487) & Mean & $0.14 \pm 0.12$ & $0.57 \pm 0.26$ & $0.31 \pm 0.14$ \\
& $N$ & 35 & 35 & 36 \\
& $P$ & - & 0.28 & 0.54 \\
cat-4(e1141) & Mean & $1.91 \pm 0.41$ & $5.64 \pm 0.43$ & ND \\
& $N$ & 65 & 36 & \\
& $P$ & - & $<0.0001$ &
\end{tabular}

Also see Materials and Methods for description of egg-laying assays. $P$ value represents the significance of the difference from the no drug control.

unc-17 (putative ACh vesicle transporter, Alfonso et al., 1993) mutants, were strongly resistant to 5-HT-induced egg laying (Table 3), suggesting that normal levels of $\mathrm{ACh}$ are required for this 5-HT response. A number of levamisole-resistant mutants were also tested and gave highly variable results for unknown reasons (data not shown). We also determined that the cat4(e1141) mutant laid eggs normally in response to levamisole (Table 2), suggesting that the requirement of levamisole-induced egg laying for the HSN neurons is due to a transmitter other than 5-HT.

These results suggest that $\mathrm{ACh}$ and 5-HT act in parallel to stimulate egg laying, though other possible models are not ruled out. In order to test whether $\mathrm{ACh}$ and 5-HT are redundant excitatory transmitters for egg laying, we constructed a cha1(p1152); cat-4(e1141) double mutant. We found that the double mutant was not detectably Egl, suggesting that, although $\mathrm{ACh}$ and 5-HT are strong inducers of egg laying, even a dearth of both transmitters does not prevent egg laying.

\section{Tricyclics can activate egg-laying independently of the HSN} neurons and 5-HT

In order to test the specificity of action of tricyclic antidepressants, we used egl-l to remove the HSN neurons and cat$4($ el 14l) to remove 5-HT. cat-4(e1141) laid eggs well in response to tricyclics, as shown for imipramine (Fig. 4, Table 1), suggesting that 5-HT is not required for tricyclic-induced egg laying. egl-l mutants were previously reported not to lay eggs in response to imipramine (Trent et al., 1983; Desai and Horvitz, 1989). While both our tests and previous tests of egl-l mutants show a sharply reduced response to tricyclics, there was still a significant stimulation of egg laying when compared to the no drug control (Table 1). These data are very similar to those previously reported (Trent et al., 1983; Desai and Horvitz, 1989), but we interpret them to indicate an $\mathrm{HSN}$-independent action of imipramine. Supporting our interpretation, the closely related tricyclic antidepressant clomipraminc, which potcntiates egg laying more strongly than imipramine, shows a more robust induction of egg laying in egl-l mutants. It was possible that the activity of the tricyclic antidepressants in egl-1 and cat-4 mutants is a result of low levels of 5-HT in the neuromuscular junction of each mutant. To test this possibility, we measured response to tricyclics of the cat-4(e1141) egl-1(n986) double mutant, and found that it responded to imipramine at least as strongly as the egl-1(n986) single mutant (Table 1; see below for analysis of clomipramine). It is conceivable that, even in the egl-1 cat-4 double mutant, there is enough 5-HT present to give

\begin{tabular}{|c|c|c|c|}
\hline Genotype & & No drug & $5-\mathrm{HT}$ \\
\hline \multirow[t]{3}{*}{ Wild type } & Mean & $1.24 \pm 0.18$ & $8.00 \pm 0.38$ \\
\hline & $N$ & 161 & 197 \\
\hline & $P$ & - & $<0.0001$ \\
\hline \multirow[t]{3}{*}{ cha-1(p1152) } & Mean & $0.08 \pm 0.37$ & $0.42 \pm 0.81$ \\
\hline & $N$ & 36 & 36 \\
\hline & $P$ & - & 0.14 \\
\hline \multirow[t]{3}{*}{ cha- $1(\mathrm{p} 1186 \mathrm{ts})$ at $20^{\circ}$} & Mean & $0.61 \pm 0.24$ & $2.56 \pm 0.45$ \\
\hline & $N$ & 36 & 36 \\
\hline & $P$ & - & $<0.0001$ \\
\hline \multirow{3}{*}{$\operatorname{cha}-1(\mathrm{p} 1186 t s)$ at $25^{\circ}$} & Mean & $0.03 \pm 0.03$ & $0.44 \pm 0.16$ \\
\hline & $N$ & 36 & 36 \\
\hline & $P$ & - & 0.09 \\
\hline \multirow[t]{3}{*}{$u n c-17(e 245)$} & Mean & $1.31 \pm 0.28$ & $1.42 \pm 0.27$ \\
\hline & $N$ & 36 & 36 \\
\hline & $P$ & - & 0.79 \\
\hline \multirow[t]{3}{*}{ unc- $17(p 300)$} & Mean & $1.67 \pm 0.33$ & $1.85 \pm 0.32$ \\
\hline & $N$ & 36 & 33 \\
\hline & $P$ & - & 0.60 \\
\hline \multirow[t]{3}{*}{$u n c-75(e 950)$} & Mean & $1.31 \pm 0.23$ & $1.43 \pm 0.28$ \\
\hline & $N$ & 35 & 35 \\
\hline & $P$ & - & 0.94 \\
\hline
\end{tabular}

See Materials and Methods and the Table 2 caption for description of egglaying assays. $P$ value represents the significance of the difference from the no drug control.

a tricyclic-induced egg-laying response. However, coupled with our findings on SSRIs and on egl-2(n693), described below, these results strongly suggest a nonserotonergic action of the tricyclic antidepressants.

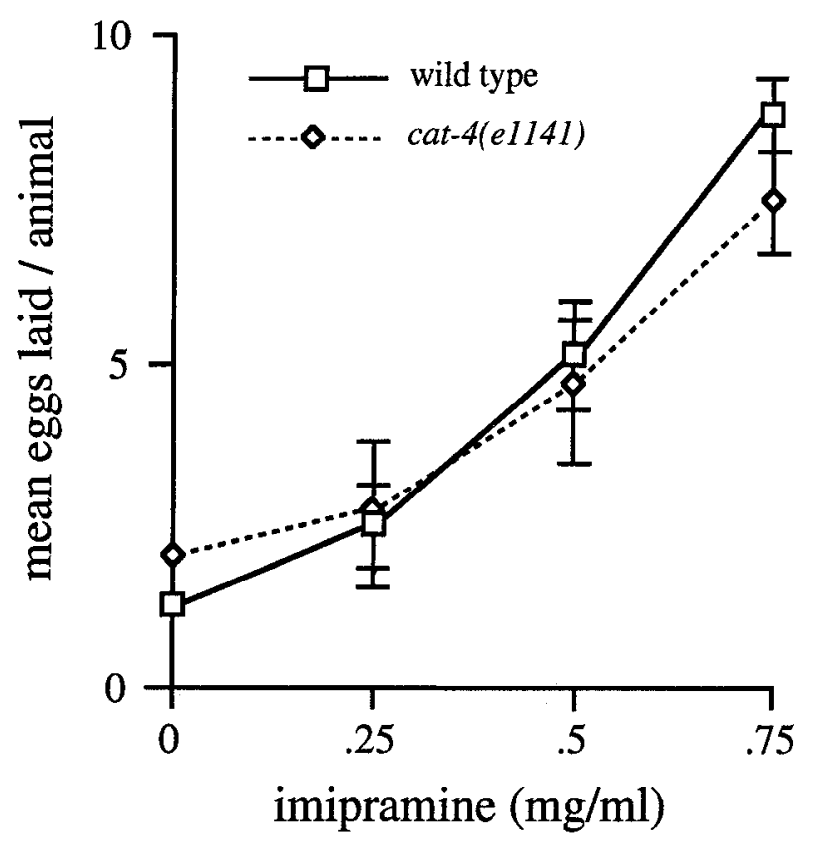

Figure 4. Dose response to imipramine of wild type and cat-4(e1141) egg laying. See Materials and Methods and the Table 2 caption for description of egg-laying assays and graph symbols. At least 12 animals were assayed for éach data point. 


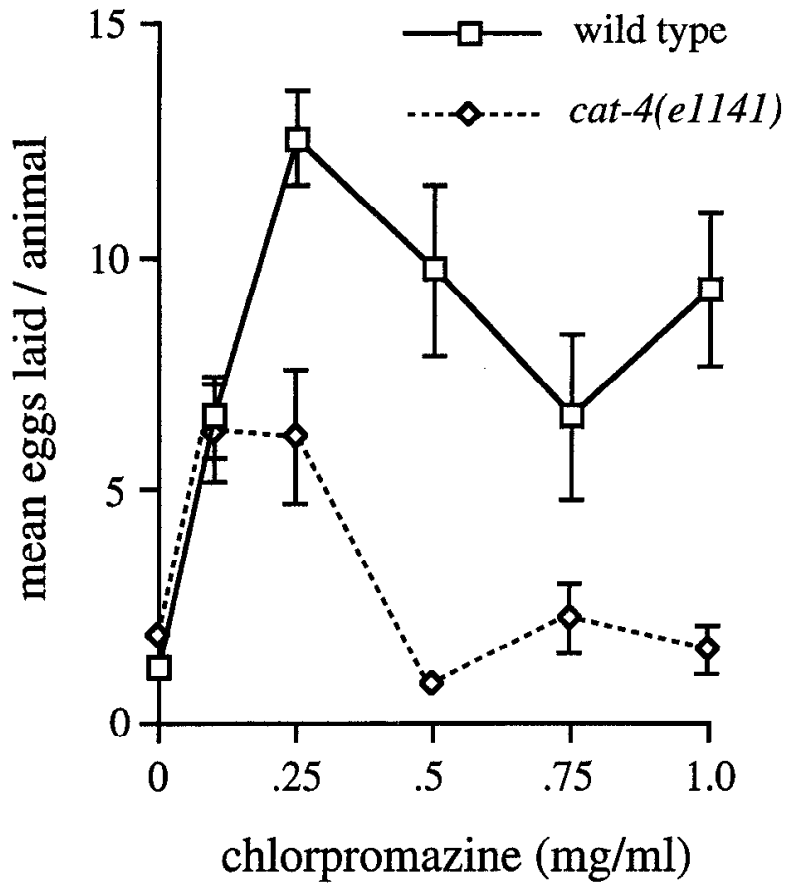

Figure 5. Dose response to chlorpromazine of wild type and cat4(e1141) egg laying. See Materials and Methods and the Table 2 caption for description of egg-laying assays and graph symbols. At least 12 animals were assayed for each data point.

cat-4(e1141) is hypersensitive to tricyclic antidepressants and dopamine antagonists

The cat-4 mutant appeared to be somewhat resistant to the high concentrations of clomipramine and other tricyclic antidepressants typically used in egg-laying assays (Table 1 and data not shown). However, even in the wild type, concentrations of these drugs that exceed $1 \mathrm{mg} / \mathrm{ml}$ inhibit, rather than induce, egg laying in the wild type (data not shown). Animals bathed in these high concentrations of tricyclics show a characteristic set of phenotypes: paralysis, kinked body posture, absence of pumping, hypercontracted nose muscles, and an absence of egg laying. cat4(e1141) animals exhibited all of these phenotypes at lower concentrations of all tricyclics tested, including imipramine and clomipramine (data not shown). This drug hypersensitivity was especially clear for the egg-laying response to chlorpromazine (Fig. 5), a putative $\mathrm{D}_{2}$ dopamine antagonist that we have found stimulates egg laying (see below). Chlorpromazine induced egg laying in wild-type animals at concentrations as high as $1 \mathrm{mg} /$ ml. In contrast, chlorpromazine concentrations up to, but not exceeding, $0.25 \mathrm{mg} / \mathrm{ml}$ stimulated egg laying in cat-4(e1141). In addition, cat-4(e1141) laid more eggs than wild type at $0.05 \mathrm{mg} /$ $\mathrm{ml}$ chlorpromazine (not shown). These results suggest that cat$4(e 1141)$ is hypersensitive to chlorpromazine and tricyclics.

The egg-laying response of the cat-4 egl-1 double mutant to clomipramine and chlorpromazine, while significantly greater than the no drug control, was considerably less than the egl-1 mutant alone (Table 1). Since cat-4 is hypersensitive to these drugs, we tested whether lower concentrations of the drugs could elicit a stronger response in the cat-4 egl-1 double mutant. The egg-laying response of the double mutant was more than doubled by a twofold reduction in the chlorpromazine concentration and more than tripled by reducing the clomipramine concentration to $0.75 \mathrm{mg} / \mathrm{ml}$ (Table 1). These results suggest that the reduced egg-laying response of cat-4 and the cat-4 egl-1 double mutant to clomipramine and chlorpromazine is due to the hypersensitivity of cat-4 to these drugs.

\section{Analysis of the dominant egl-2(n693) mutation}

The pharmacological responses of the vast majority of egg-laying defective mutants can be explained by the model for egg laying given in Figure 1 (Trent et al., 1983). One exception is egl-2(n693), a mutant that is severely Egl and lays eggs well in response to imipramine but not in response to 5-HT (Table 4; Trent et al., 1983). We first assumed that the egg-laying model is correct, and we considered two possible explanations of the egl-2(n693) pharmacology. First, the imipramine response and 5-HT resistance of egl-2(n693) might be caused by two different mutations. This possibility is ruled out by the isolation of a second dominant allele of $e g l-2$. The $n 2656$ allele (graciously provided by $E$. Jorgensen) maps to the same small genetic interval as egl-2 (our unpublished data) and causes precisely the same phenotypes as $n 693$ in both pleiotropic defects and pharmacology (data not shown). Second, we considered the hypothesis that the egl-2(n693) mutation blocks egg laying by causing hyperactive reuptake of 5-HT by the HSN neurons: exogenous 5-HT

Table 4. Quantitative egl-2(n693) pharmacology

\begin{tabular}{|c|c|c|c|c|c|c|c|}
\hline \multirow[b]{2}{*}{ Drug } & \multicolumn{3}{|c|}{$\begin{array}{l}\text { egl-2(n693) egg-laying } \\
\text { (well assays) }\end{array}$} & \multicolumn{4}{|c|}{$\begin{array}{l}e g-2(n 693) \text { defecation } \\
\text { (plate assays) }\end{array}$} \\
\hline & mean eggs & $N$ & $P$ & $\% \mathrm{EMC}$ & $N$ & \#DMPs & $P$ \\
\hline No drug & $0.03 \pm 0.03$ & 36 & - & $1.0 \% \pm 0.7 \%$ & 10 & 134 & - \\
\hline $5-\mathrm{HT}$ & $0.17 \pm 0.06$ & 66 & 0.43 & $1.4 \%+1.0 \%$ & 10 & 143 & 0.74 \\
\hline Inipipranine & $5.14 \pm 0.32$ & 95 & $<0.0001$ & $94.0 \% \pm 2.4 \%$ & 10 & 129 & $<0.0001$ \\
\hline Clomipramine & $8.00 \pm 0.59$ & 36 & $<0.0001$ & $81.5 \% \pm 4.6 \%$ & 7 & 99 & $<0.0001$ \\
\hline Chlorpromazine & $5.17 \pm 0.61$ & 35 & $<0.0001$ & $94.3 \% \pm 3.5 \%$ & 5 & 43 & $<0.001$ \\
\hline Haloperidol & $3.33 \pm 0.50$ & 36 & $<0.0001$ & $84.1 \% \pm 4.1 \%$ & 5 & 58 & $<0.001$ \\
\hline Phentolamine & $0.30 \pm 0.12$ & 30 & 0.21 & $88.4 \% \pm 3.4 \%$ & 5 & 55 & $<0.001$ \\
\hline Fluoxetine & $0.17 \pm 0.12$ & 36 & 0.84 & $1.4 \% \pm 1.4 \%$ & 5 & 45 & 0.77 \\
\hline
\end{tabular}

$N$, Number of animals tested. mean eggs, mean number of eggs laid per animal. \#DMPs, The number of times the animals initiated the defecation motor program. \%EMC, The percent of DMP initiations that resulted in an active enteric muscle contraction. The $P$ value represents the significance of the difference from the no drug control. Drug concentrations were as follows: 5 -HT and phentolamine $(10 \mathrm{mg} / \mathrm{ml})$, imipramine $(0.75 \mathrm{mg} / \mathrm{ml})$, and clomipramine, chlorpromazine, haloperidol, fluoxetine $(1 \mathrm{mg} / \mathrm{ml}$ ). The no drug control for egg laying was M9 buffer (see Materials and Methods). Defecation assays were performed as described in Materials and Methods. 
Table 5. Effects of various drugs on defecation in the wild type

\begin{tabular}{llrrrc} 
& & \multicolumn{4}{l}{ \#DM- } \\
Drug & Genotype & $N$ & Ps & \%EMC & $P$ \\
\hline No drug & Wild type & 10 & 134 & $98.5 \% \pm 0.01 \%$ & - \\
5-HT & Wild type & 5 & 78 & $38.6 \% \pm 0.03 \%$ & $<0.001$ \\
Dopamine & Wild type & 5 & 77 & $42.2 \% \pm 0.04 \%$ & $<0.001$ \\
Imipramine & Wild type & 5 & 58 & $97.0 \% \pm 0.02 \%$ & 0.59 \\
No drug & unc-43(e266) & 3 & 24 & $84.2 \% \pm 0.08 \%$ & - \\
Octopamine & unc-43(e266) & 3 & 33 & $3.2 \% \pm 0.02 \%$ & 0.008
\end{tabular}

Defecation assays were performed as described in Materials and Methods, with the exception of assays on unc-43(e266), which were assayed on plates containing no food for the no drug control. Each animal was assayed for $10 \mathrm{~min}$. $N$, Number of animals tested. \#DMPs, The number of times the animals initiated the defecation motor program. \%EMC, The percent of DMP initiations that resulted in an active enteric muscle contraction. The $P$ value represents the significance of the difference from the no drug control. Drug concentrations were used as follows: octopamine $(20 \mathrm{mg} / \mathrm{ml}), 5-\mathrm{HT}(10 \mathrm{mg} / \mathrm{ml})$, dopamine $(6$ $\mathrm{mg} / \mathrm{ml})$, and imipramine $(0.75 \mathrm{mg} / \mathrm{ml})$.

is ineffective in stimulating egg laying because of this hyperreuptake, but imipramine blocks this reuptake, allowing endogenous 5-HT to excite the egg-laying muscles. We conducted several experiments that test the hyper-reuptake hypothesis in four ways, and the results of these experiments together argue strongly against this hypothesis. (1) In addition to being $\mathrm{Egl}, \mathrm{egl}$ 2(n693) mutants also exhibit a weak kinker Unc phenotype, have a male mating defect (Trent et al., 1983), and are severely constipated (Con) due to an inability to activate the enteric muscles used in defecation (Table 4 ). If egl-2(n693) causes all of its pleiotropic defects because of hyperactive 5-HT reuptake, then 5-HT should activate enteric muscle contractions (EMCs) in the wild type, since the egl-2(n693) mutation inhibits EMCs. Instead, 5-HT inhibits EMCs in the wild type (Table 5; Ségalat et al., 1995). Furthermore, imipramine does not detectably affect EMCs in the wild type, while imipramine and several other tricyclics, but not 5-HT, rescue the EMC defect in egl-2(n693) (Tables 4-6). These results suggest that the imipramine rescue of the EMC defect of $e g l-2(n 693)$ is unrelated to 5-HT reuptake. (2) If egl-2(n693) caused a hyper-reuptake of 5-HT only by the HSN neurons, then egl-2(n693) animals lacking these neurons would lay eggs in response to exogenous 5-HT. However, the double mutant between egl-2(n693) and egl-l(n487), which lacks HSN neurons, still did not lay eggs in response to 5-HT (Table 7). It remained possible that egl-2(n693) causes ectopic expression of a 5-HT reuptake function. Since $C$. elegans will load exogenous 5-HT into neurons that take up 5-HT (Loer and Kenyon, 1993), this possibility predicts that egl-2(n693) animals will load 5-HT into additional cells. This is ruled out by the fact that egl-2(n693) animals were indistinguishable from the wild type when treated with exogenous 5-HT and stained with anti5-HT antibody (data not shown). (3) If the hyper-reuptake hypothesis were correct, animals lacking 5-HT should have a phenotype similar to animals with a hyper-reuptake defect. However, none of the cat-4(e1141), bas-1(ad446), or cat-4; bas-1 double mutants are Egl (see above) or EMC defective (data not shown). (4) If imipramine induces egg laying in egl-2(n693) by blocking reuptake of 5 -HT, then endogenous 5 -HT should be required for the imipramine response. However, egl-2(n693) cat4(e1141) and bas-1(ad446); egl-2(n693) double mutants still laid eggs in response to imipramine (Table 8 ).

Taken together, these results indicate that $e g l-2(n 693)$ causes neither hyper-reuptake of 5-HT by the HSN neurons nor ectopic
Table 6. Qualitative egl-2(n693) pharmacology

\begin{tabular}{|c|c|c|c|}
\hline Drug & Description & $\begin{array}{l}\text { Egg } \\
\text { laying }\end{array}$ & $\begin{array}{l}\text { Defeca- } \\
\text { lionl }\end{array}$ \\
\hline Water or M-9 & No drug control & - & - \\
\hline $5-\mathrm{HT}$ & Neurotransmitter & - & - \\
\hline Ketanserin & $\begin{array}{l}\text { Metabotropic 5-HT receptor } \\
\text { antagonist }{ }^{b}\end{array}$ & - & - \\
\hline Methiothepin & $\begin{array}{l}\text { Metabotropic 5-HT receptor } \\
\text { antagonist }\end{array}$ & - & - \\
\hline Clozapine & 5-HT and dopamine antagonist ${ }^{d}$ & - & - \\
\hline ICS205930 & $\begin{array}{l}\text { Ionotropic 5-HT receptor (5- } \\
\mathrm{HT}_{3} \text { ) antagonist }\end{array}$ & $+1-$ & $+1-$ \\
\hline Imipramine & $\begin{array}{l}\text { Tricyclic biogenic amine } \\
\text { rcuptake inhibitorf }\end{array}$ & + & ++ \\
\hline Clomipramine & $\begin{array}{l}\text { Tricyclic biogenic amine } \\
\text { reuptake inhibitor } f\end{array}$ & + & ++ \\
\hline Amitriptiline & $\begin{array}{l}\text { Tricyclic biogenic amine } \\
\text { reuptake inhibitor }\end{array}$ & + & ++ \\
\hline Desipramine & $\begin{array}{l}\text { Tricyclic biogenic amine } \\
\text { reuptake inhibitor }\end{array}$ & - & - \\
\hline Nortriptiline & $\begin{array}{l}\text { Tricyclic biogenic amine } \\
\text { reuptake inhibitor }\end{array}$ & $+1-$ & - \\
\hline Fluoxetine & $\begin{array}{l}\text { Selective 5-HT reuptake } \\
\text { inhibitor }^{f}\end{array}$ & - & - \\
\hline Paroxetine & $\begin{array}{l}\text { Selective } 5 \text {-HT reuptake } \\
\text { inhibitor }\end{array}$ & - & - \\
\hline Sertraline & $\begin{array}{l}\text { Selective 5-HT reuptake } \\
\text { inhibitor }\end{array}$ & - & - \\
\hline Levamisole & Nicotinic ACh agonist ${ }^{g}$ & - & - \\
\hline Pirenzapine & Muscarinic $\mathrm{ACh}$ antagonist ${ }^{h}$ & - & - \\
\hline Prazosin & Alpha adrenergic antagonist ${ }^{i}$ & - & - \\
\hline Phentolamine & $\begin{array}{l}\text { Octopamine and alpha } \\
\text { adrenergic antagonis }{ }^{j}\end{array}$ & $+1-a$ & ++ \\
\hline Bicuculline & GABA antagonist ${ }^{k}$ & - & - \\
\hline Dopamine & Neurotransmitter & - & - \\
\hline Nomifensine & Dopamine reuptake blocker ${ }^{l}$ & - & - \\
\hline Chlorpromazine & D2 family dopamine antagonist ${ }^{m}$ & + & ++ \\
\hline Haloperidol & D2 family dopamine antagonist ${ }^{m}$ & + & ++ \\
\hline Butaclamol & D2 family dopamine antagonist ${ }^{n}$ & + & ++ \\
\hline Droperidol & D2 family dopamine antagonist ${ }^{\circ}$ & + & ++ \\
\hline Pimozide & D2 family dopamine antagonist ${ }^{p}$ & + & ++ \\
\hline Loxapine & $\begin{array}{l}\text { D1/D2 family dopamine } \\
\text { antagonist }{ }^{q}\end{array}$ & - & - \\
\hline $\mathrm{SCH} 23390$ & D1 family dopamine antagonist ${ }^{m}$ & - & - \\
\hline
\end{tabular}

Egg-laying experiments were done in well assays as described in Materials and Methods. At least 12 worms were assaycd for each drug in wclls. Drug concentrations were as follows: 5-HT, dopamine, phentolamine $(10 \mathrm{mg} / \mathrm{ml}) \mathrm{lev}$ amisole $(100 \mu \mathrm{g} / \mathrm{ml})$, and tricyclic antidepressants and all other antagonists $(0.75 \mathrm{mg} / \mathrm{ml})$. Defecation assays were performed as described in Materials and Methods. \%EMC, The percent of DMP initiations that resulted in an active enteric muscle contraction. Qualitative egg-laying assays were performed as described in Materials and Methods. The description column indicates reported pharmacological activity in mammalian systems, except phentolamine which was studied in the locust. Egg laying: $(-)=0-1$ eggs/animal, $(+/-)=1-3$ eggs/animal, $(+)=4-8$ eggs/animal, $(++)=>8$ eggs/animal. Defecation: $(-)<10 \%$ EMC,$(+/-)=11-30 \%$ EMC,$(+)=31-80 \%$ EMC,$(++)=81-$ $100 \%$ EMC.

a egl-2(n693) did not lay eggs in well assays (Table 1) but did lay eggs on plates in response to phentolamine.

${ }^{b}$ Hedner and Persson (1988); ${ }^{c}$ Mylecharane (1989); ${ }^{d}$ Ereshefsky et al. (1989); e Richardson et al. (1985); $f$ Hyttel $(1994) ;{ }^{8}$ I ewis et al. (1980); ${ }^{h}$ Stockhrugger (1989); ' Nash (1990); ${ }^{j}$ Evans and O'Shea (1978), Dylund (1992), and Horvitz et al. (1982); ${ }^{k}$ Curtis et al. (1970); ' Kinney (1985); ${ }^{m}$ Sunahara et al. (1993);

"Seeman (1987); ${ }^{\circ}$ Hamik and Peroutka (1989); ${ }^{\circ}$ Giannini et al. (1984-1985); ${ }^{q}$ Anderson et al. (1986). 


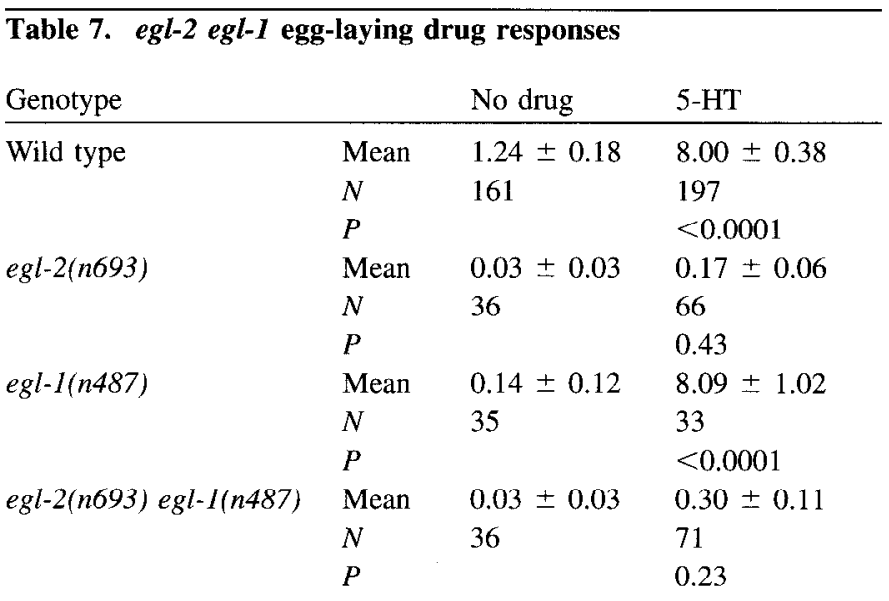

See Materials and Methods and Table 2 caption for description of egg-laying assays. The $P$ value represents the significance of the difference from the nn drug control.

expression of 5-HT reuptake, and suggest that the imipramine rescue of the $\mathrm{Egl}$ and Con phenotypes is unrelated to 5-HT function. An additional observation that bears on this point is that two of the muscle groups affected by the egl-2(n693) mutation appear to use different primary excitatory neurotransmitters: 5HT (Trent et al., 1983; Desai and Horvitz, 1988) and possibly ACh (see above) for the egg laying muscles and GABA for the enteric muscles (Thomas, 1990; McIntire et al., 1993a,b). No transmitters that are known to stimulate egg-laying in wild-type animals do so in egl-2(n693). These facts suggest that the egl2(n693) phenotypes are not caused by a deficiency of any single excitatory transmitter, and suggest that imipramine has some target in C. elegans other than 5-HT reuptake.

\section{egl-2(n693) is rescued by tricyclic antidepressants and} dopamine antagonists

Our results suggest that egl-2(n693) does not affect a serotonergic pathway, but does not suggest any alternative explanation. In the hope of finding such an explanation, we investigated the pharmacological specificity of the $\mathrm{Egl}$ and Con rescue of egl- 2(n693). We treated egl-2(n693) animals with a battery of neurotransmitter agonists and antagonists and measured the rescue of the $\mathrm{Egl}$ and $\mathrm{Con}$ phenotypes. Included among the drugs were ones that affect 5-HT, GABA, dopamine, and ACh pathways in mammals and octopamine, since each of these transmitter systems is implicated in egg laying (Horvitz et al., 1982; Trent et al., 1983; Schafer and Kenyon, 1995; our data not shown). We found that two distinct classes of drugs were able to strongly rescue both of the egl-2(n693) phenotypes assayed: tricyclic antidepressants related to imipramine and several $\mathrm{D}_{2}$ family dopamine antagonists such as chlorpromazine and haloperidol (Tables 4,6 ). In addition, phentolamine, an octopamine antagonist in invertebrates (Evans and O'Shea, 1978; Horvitz et al., 1982), was effective in stimulating EMCs but only weakly rescued the egg-laying defect (Tables 4, 6).

egl-2(n693) may activate an inhibitory pathway in the egglaying and enteric muscles

Since our data suggest that the Egl phenotype of egl-2(n693) is not caused by a defect in the HSN neurons, the only motor neurons required for egg laying (Desai et al., 1988), we hypothesized that egl-2(n693) causes a defect in muscle. Inappropriate activation of a negative regulatory pathway in the egg-laying and enteric muscles could account for the egl-2(n693) phenotypes (Fig. 6). A clue to the nature of such an inhibitory pathway comes from evidence that tricyclic antidepressants can antagonize $\mathrm{D}_{2}$ dopamine receptors (Austin et al., 1991; Smialowski et al., 1991). Since dopamine antagonists can rescue egl-2(n693), we hypothesized that $e g l-2(n 693)$ activates a negative regulatory dopaminergic pathway that can be blocked by tricyclics and $\mathrm{D}_{2}$ dopamine antagonists. Consistent with this model, dopamine inhibits both egg laying (Horvitz et al., 1982; Schafer and Kenyon, 1995; our data not shown) and EMCs (Table 5) in the wild type. Based on the partial rescue of egl-2(n693) by phentolamine, an octopamine antagonist, we also tested the possibility that egl2(n693) activates an octopaminergic pathway. Octopamine also inhibits egg laying in the wild type (Horvitz et al., 1982), but we were unable to determine its effect on EMCs in the wild type because it prevents the initiation of the defecation motor program (DMP). We used a loss of function mutation in unc-43,

\begin{tabular}{|c|c|c|c|c|}
\hline Genotype & & No drug & 5-HT & Imipramine \\
\hline \multirow[t]{3}{*}{ Wild type } & Mean & $1.24 \pm 0.18$ & $8.00 \pm 0.38$ & $10.01 \pm 0.33$ \\
\hline & $N$ & 161 & 197 & 162 \\
\hline & $P$ & - & $<0.0001$ & $<0.0001$ \\
\hline \multirow[t]{3}{*}{$e g l-2(n 693)$} & Mean & $0.03 \pm 0.03$ & $0.17 \pm 0.06$ & $5.14 \pm 0.32$ \\
\hline & $N$ & 36 & 66 & 95 \\
\hline & $P$ & - & 0.43 & $<0.0001$ \\
\hline \multirow[t]{3}{*}{$\operatorname{cat}-4(e 1141)$} & Mean & $1.91 \pm 0.41$ & $7.44 \pm 1.01$ & $7.50 \pm 0.79$ \\
\hline & $N$ & 65 & 36 & 36 \\
\hline & $P$ & - & $<0.0001$ & $<0.0001$ \\
\hline \multirow[t]{3}{*}{ egl-2(n693) cat-4(ell4I) } & Mean & $0.42 \pm 0.16$ & $0.25 \pm 0.13$ & $3.25 \pm 0.70$ \\
\hline & $N$ & 36 & 36 & 32 \\
\hline & $P$ & - & 0.46 & 0.001 \\
\hline \multirow[t]{3}{*}{ bas-1(ad446); egl-2(n693) } & Mean & $0.03 \pm 0.03$ & $0.30 \pm 0.17$ & $6.91 \pm 0.47$ \\
\hline & $N$ & 34 & 30 & 32 \\
\hline & $P$ & - & 0.45 & $<0.0001$ \\
\hline
\end{tabular}

See Materials and Methods and Table 2 caption for description of egg-laying assays. The $P$ value represents the significance of the difference from the no drug control. 


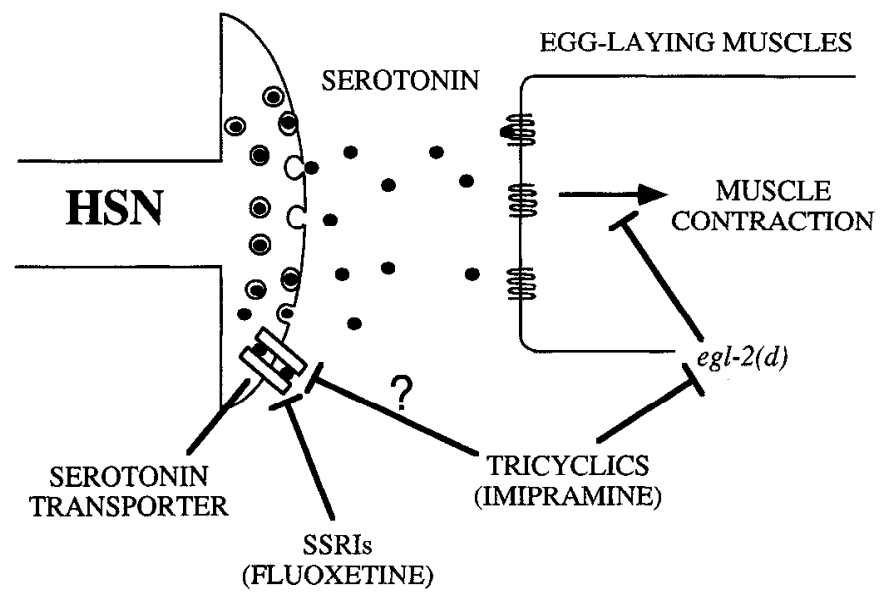

Figure 6. Formal model for egl-2 and the action of tricyclics and SSRIs. ACh may act in parallel to 5-HT but is not shown in the figure because the site of action of ACh is not known. egl-2(n693) causes activation of an inhibitory pathway acting in or on the egg-laying muscles. Tricyclics induce egg laying in egl-2(n693) by blocking this inhibitory pathway, and they may also block 5-HT reuptake. SSRIs specifically block 5-HT reuptake without affecting the egl-2(n693) pathway. Arrows represent a positive interaction and bars represent a negative interaction.

which activates DMPs constitutively (Liu and Thomas, 1994; D. Reiner and J. Thomas, unpublished data), to assay the effect of octopamine on EMCs. In unc-43(e266) animals, octopamine inhibited both EMCs and anterior body contractions (Table 5), another step in the DMP. We conclude that activation of a dopaminergic or octopaminergic pathway could account for the egl-2(n693) phenotypes.

The site of activation of an inhibitory pathway by egl-2(n693) could be pre- or postsynaptic. Two lines of evidence argue against a presynaptic site. First, if egl-2(n693) causes excess dopamine to be released, removing dopamine should relieve the egl-2(n693) phenotypes. cat-4(e1141) mutants, in addition to lacking 5-HT, have sharply reduced levels of dopamine (Sulston et al., 1975). However, the egl-2(n693) cat-4(e1141) double mutant is as severely Egl, 5-HT resistant, and Con as egl-2(n693) alone (Table 8 and data not shown). Second, elimination of either class of neurons that is known to synapse with the egglaying muscles, the HSN neurons and the VC neurons, failed to rescue the Egl phenotype of egl-2(n693). egl-2(n693); egl-l animals lacking HSN neurons were as severely Egl and 5-HT resistant as $e g l-2(n 693)$ alone, even though $e g l-l$ animals respond normally to 5-HT (Table 7, data not shown, and Trent et al., 1983). The lin-39(n709ts) mutation causes the VC neurons to die, but a lin-39(n709ts); egl-2(n693) double mutant was still severely Egl (see Materials and Methods). Furthermore, tricyclic antidepressants have been shown to have effects on postsynaptic receptors, while dopamine antagonists are not known to have any presynaptic targets. These results suggest that the egl2(n693) mutation causes inappropriate activation of an inhibitory pathway in the egg-laying and enteric muscles that can be blocked by tricyclic antidepressants, $D_{2}$ family dopamine antagonists, and, to a lesser degree, phentolamine.

The tricyclics and dopamine antagonists differ from SSRIs in inducing egg laying in a 5-HT- and HSN-independent manner

Since $e g l-2(n 693)$ is a dominant mutation, there remained the possibility that the drugs act on an egl-2(n693)-mediated egg- laying pathway that does not exist in the wild type. We have two lines of evidence that suggest that the egl-2(n693)-mediated pathway is present in $e g l-2(+)$ animals.

First, if the egl-2 pathway were present in the wild type, then we might be able to find evidence for induction of egg laying by tricylics and $\mathrm{D}_{2}$ family dopamine antagonists in mutants that affect 5-HT and dopamine function. We found that tricylics and chlorpromazine induced egg laying in the wild type and in the cat-4(e1141) mutant (Table 1 and data not shown). We also found significant, though reduced, induction of egg laying by both classes of drugs in egl-1 mutants (Table 1 and data not shown). These findings are consistent with the hypothesis that both classes of drugs act on an inhibitory pathway for egg laying that is present in the wild type.

Second, if the tricyclic antidepressant rescue of egl-2(n693) were due to a lack of pharmacological specificity for 5-HT reuptake, we hypothesized that more specific 5-HT reuptake blockers might induce egg laying in an HSN and 5-HT-dependent manner and fail to induce egg-laying in egl-2(n693). Prozac (fluoxetine) is one of the best-studied antidepressants, and has been shown to block 5-HT reuptake more specifically than the tricyclics (Hyttel, 1993). We found that fluoxetine induced egg-laying in the wild type but not in egl-2(n693) (Tables 1, 4). Furthermore, this induction was fully dependent on egl-1 (Table 1) and cat-4 (Fig. 3). We conclude that $C$. elegans possesses a fluoxetinesensitive 5-HT reuptake system and that, in contrast to the tricyclics, the effect of fluoxetine on egg laying is 5-HT dependent. We tested the activity of two other selective 5-HT reuptake inhibitors that induce egg laying in the wild type, paroxetine and sertraline (data not shown), and neither was able to induce egg laying nor EMCs in egl-2(n693) (Table 6). In contrast, several different tricyclic drugs, which are structurally related to imipramine and are reported to be relatively promiscuous in their pharmacological effects (Hyttel, 1993), can rescue both the Egl and Con phenotypes of egl-2(n693) (Table 6). We conclude that there exists a close parallel between the 5-HT-independent induction of egg laying by tricyclics, but not SSRIs, in egl-2(+) animals, and the pattern of suppression of egl-2(n693) mutant defects.

\section{Discussion}

A revision of the $\mathrm{C}$. elegans egg-laying model

We report pharmacological analysis of egg laying in the wild type and several mutants that perturb neurotransmitter levels, motor neuron function, or other aspects of the egg-laying system in $C$. elegans. Our findings extend our understanding of egg laying in two main ways. First, they suggest a more complex model for egg laying in the wild type that includes action of several transmitters, possibly acting in parallel. Second, our findings resolve an apparent conflict between the pharmacology of egg laying in the wild type and in the mutant egl-2(n693).

Previously, the simplest model for egg laying held that 5-HT is necessary and sufficient for normal egg laying. We present evidence that 5-HT is not required for egg laying. Furthermore, our data that $\mathrm{ACh}$-deficient mutants are resistant to 5-HT-induced egg laying suggest that 5-HT is not sufficient for egg laying. We suggest that 5-HT and ACh act in parallel as cotransmitters on the egg-laying muscles. However, our data suggest that a deficiency in both transmitters still does not cause a defect in egg laying. Since ACh-induced egg laying requires the HSN neurons, but not 5-HT, we hypothesize the presence of a third transmitter in the HSN neurons that induces egg laying. Killing 
the HSN neurons causes an Egl phenotype by removing this third transmitter or by removing a combination of transmitters. The complex modulation of behaviors by multiple neurotransmitters is not well understood. It would appear that activation of the egg-laying muscles in $C$. elegans is surprisingly complex and is ripe for further pharmacological and genetic analysis.

According to previous models for egg laying, imipramine induces egg laying only by blocking reuptake of 5-HT by the HSN neurons. Our results show that the action of imipramine and related tricyclics is not this simple. However, fluoxetine and other SSRIs appear to have the specificity in C. elegans egg laying that the tricyclics lack. These apparent targets and specificities of fluoxetine and tricyclic antidepressants in C. elegans parallel those seen in mammals, suggesting that $C$. elegans provides a genetic model for the study of these psychoactive drugs.

\section{The mechanism of the egl-2(n693) defect}

Our studies of $e g l-2$ not only offer a resolution of its unexplained pharmacological properties, but also suggest novel aspects of egg laying in the wild type. We show that egl-2(n693) does not cause a hyper-reuptake of 5-HT by the HSN neurons or ectopic expression of 5-HT reuptake, but instead probably causes the inappropriate activation of a pathway that negatively regulates muscle excitation. In addition, we show that the imipramine rescue of egl-2(n693) is independent of its ability to block 5-HT reuptake. The ability of dopamine to inhibit egg laying and EMC's in the wild type, coupled with the rescue of egl-2(n693) by dopamine antagonists, implicates this transmitter in the $e g l-2$ pathway and suggests a common site of action for $\mathrm{D}_{2}$ dopamine antagonists and tricyclic antidepressants.

Since egl-2(n693) is a dominant mutation, there is the possibility that the egl-2(+) gene product neither functions in these pathways nor interacts with tricyclic antidepressants. However, the fact that the drugs that induce egg laying in egl-2(n693) can also induce egg laying in the wild type in an HSN and 5-HTindependent manner supports a role for egl-2 in normal egg laying. Although our data are consistent with egl-2(n693) causing inappropriate activation of an inhibitory dopamine or octopamine pathway, we favor the dopamine hypothesis for three reasons. First, the induction of egg laying in egl-2(n693) by phentolamine is relatively weak. Second, cat-4(e1141), which is deficient in 5-HT and dopamine, is hypersensitive to a number of the drugs that rescue egl-2(n693). A possible explanation for this hypersensitivity is that the dopamine deficiency of cat-4 causes an alteration of dopaminergic responsiveness. Third, there is evidence in other systems that tricyclic antidepressants can antagonize $D_{2}$ family dopamine receptors (Austin et al., 1991; Smialowski, 1991). In spite of this evidence, we cannot rule out the possibility that egl-2(n693) activates an octopaminergic or some other unspecified pathway. For example, the octopamine receptor may not be fully inhibited by phentolamine, and cat-4(e1141) may be hypersensitive to the egl-2-rescuing drugs for other, as yet undetermined reasons. Since all five cloned dopamine receptor genes encode G-protein coupled seven-pass transmembrane proteins (Sunahara et al., 1993), it is reasonable to hypothesize that egl-2(n693) causes activation of a metabotropic pathway that results in muscle inhibition indirectly, but we cannot rule out the possibility that egl-2(n693) affects a novel ionotropic dopamine receptor. This model makes predictions about the consequences of loss of egl-2 function. Four revertants of $e g l-2(n 693)$ exist (C. Trent and H. R. Horvitz, personal communication), but it is unestablished whether or not they cause loss of $e g l-2$ function. These revertants appear to be grossly wild type and remain responsive to imipramine and dopamine. Further genetic and molecular analysis of egl-2 is required to determine the loss-of-function phenotype for egl-2 and its implication for the interaction between the $e g l-2$ gene product and tricyclic antidepressants.

While we think that a direct inhibition of egl-2 activity by the tricyclics and dopamine antagonists is the most plausible explanation for the rescue of egl-2(n693) by these drugs, indirect effects are also possible. For instance, the tricyclics and dopamine antagonists could be activating a pathway that either blocks or bypasses the egl-2 pathway at a downstream step. Alternatively, egl-2(n693) may antagonize the egg-laying and enteric muscles in some unanticipated manner that coincidentally is blocked by tricyclic antidepressants and dopamine antagonists. These alternatives are currently difficult to distinguish because our pharmacological tests are limited whole-animal treatments. However, genes defined by mutation in $C$. elegans can readily be molecularly cloned and expression patterns, genetic mosaics, and similar approaches can be used to define specific sites of function. We are cloning egl-2 in an effort to distinguish among these models.

A general difficulty with these and other pharmacological studies in C. elegans is the fact that our inferences are based largely on the pharmacologies of these compounds in mammals, often with little direct evidence that their targets or potencies are similar in C. elegans. In support of the validity of such analysis, evidence suggests that the targets for several neuroactive drugs are impressively conserved between nematodes and mammals. These include nicotinic agonists (Lewis et al., 1980), muscimol, and nipecotic acid (GABA agonist and uptake inhibitor; McIntire et al., 1993a), metabotropic 5-HT agonists (Ségalat et al., 1995), AMPA (glutamate agonist, J. Kaplan, personal communication), and fluoxetine (this study). Further study will reveal to what degree the relative potencies of these agents, and the targets and potencies of other agents have been conserved.

\section{A common site of action for tricyclic antidepressants and dopamine antagonists in $\mathrm{C}$. elegans}

The pharmacology of egl-2(n693) provides genetic evidence that $\mathrm{D}_{2}$ dopamine antagonists and tricyclic antidepressants can act on the same target. Tricyclics are commonly used to treat depression, and $\mathrm{D}_{2}$ dopamine antagonists are therapeutic as antischizophrenics (Sunahara et al., 1993). The tricyclic clomipramine has been an effective drug in the treatment of obsessive-compulsive disorder (OCD) (McDougle et al., 1993). Recent evidence has suggested that a dopaminergic system, as well as a serotonergic system, is involved in OCD (Austin et al., 1991; McDougle et al., 1993). Specifically, patients whose OCD is refractory to 5-HT reuptake inhibitors have benefited from the addition of low-dose dopamine antagonists to their treatment regimens (McDougle et al., 1993). egl-2 may be a gene in a dopaminergic pathway that interacts with both tricyclic antidepressants and $\mathrm{D}_{2}$ dopamine antagonists. The molecular identity of this dopaminergic pathway may aid in understanding both the side effects of tricyclic drugs and their efficacy in treating OCD.

\section{References}

Alfonso A, Grundahl K, Duerr JS, Han HP, Rand JB (1993) The Caenorhabditis elegans unc-17 gene: a putative vesicular acetylcholine transporter. Science 261:617-619. 
Andersen PH, Nielsen EB, Gronvald C, Braestrup C (1986) Some atypical neuroleptics inhibit $\left[{ }^{3} \mathrm{H}\right] \mathrm{SCH} 23390$ binding in vivo. Eur J Pharmacol 120:143-144.

Austin LS, Lydiard RB, Ballenger JC, Cohen BM, Laraia MT, Zealberg JJ, Fossey MD, Ellinwood EH (1991) Dopamine blocking activity of clomipramine in patients with obsessive-compulsive disorder. Biol Psychol 30:225-232.

Brenner S (1974) The genetics of Caenorhabditis elegans. Genetics 77:71-94.

Briley M (1985) Imipramine binding: its relationship with serotonin uptake and depression. In: Neuropharmacology of serotonin (Green R, ed), pp 50-70. New York: Oxford UP.

Clark SG, Chisholm AD, Horvitz IIR (1993) Control of cell fates in the central body region of $C$. elegans by the homeobox gene lin-39. Cell 74:43-55.

Croll N (1975) Integrated behaviour in the feeding phase of Caenorhabditis elegans (Nematoda). J Zool 184:507-517.

Curtis DR, Duggan AW, Felix D, Johnston GA (1970) GABA, bicuculline, and central inhibition. Nature 226:1222-1224.

Desai C, Horvitz HR (1989) Caenorhabditis elegans mutants defective in the functioning of the motor neurons responsible for egg-laying. Genetics 121:703-721.

Desai C, Garriga G, McIntire SL, Horvitz HR (1988) A genetic pathway for the development of the Caenorhabditis elegans HSN motor neurons. Nature 336:638-646.

Dylund DB (1992) Subtypes of alpha1- and alpha2-adrenergic receptors. FASEB J 6:382-389.

Ellis $H$ (1985) Genetic control of programmed cell death in the nematode Caenorhabditis elegans. Ph.D. dissertation, Department of Biology, MIT.

Ereshefsky C, Watanabe MD, Tran-Johnson TK (1989) Clozapine: an atypical antipsychotic agent. Clin Pharmacol 8:691-709.

Evans PD, O'Shea M (1978) The identification of an octopaminergic neurone and the modulation of a myogenic rhythm in the locust. $J$ Exp Biol 73:235-260.

Ferguson EL, Horvitz HR (1985) Identification and characterization of 22 genes that affect the vulval cell lineages of the nematode Caenorhabditis elegans. Genetics 110:17-22.

Fuller RW (1987) Pharmacologic properties of serotonergic agents and antidepressant drugs. J Clin Psychol Suppl 48:5-11.

Garriga G, Desai C, Horvitz IIR (1993) Cell interactions control the direction of outgrowth, branching and fasciculation of the HSN neurons of Caenorhabditis elegans. Development 117:1071-1087.

Giannini AJ, Nageotte L, Loiselle RH, Malon DA, Price WA (1984-5) Comparison of chlorpromazine, haloperidol, and pimozide in the treatment of phencyclidine psychosis: DA-2 receptor specificity. J Toxicol Clin Toxicol 22:573-579.

Hamik A, Peroutka SJ (1989) Differential interactions of traditional and novel antimetics with dopamine D2 and 5-hydroxytryptamine3 receptors. Cancer Chemother Pharmacol 25:307-310.

Hedner T, Persson B (1988) Effects of a new serotonin antagonist, ketanserin, in experimental and clinical hypertension. Am J Hypertens 1:3175-3235.

Horvitz HR, Chalfie M, Trent C, Sulston J, Evans P (1982) Serotonin and octopamine in the nematode Caenorhabditis elegans. Scicnce 216:1012-1014.

Hyttel J (1994) Pharmacological characterization of selective serotonin reuptake inhibitors (SSRIs). Int Clin Psychopharmacol Suppl 9:1926.

Kinney JL (1985) Nomifensine maleate: a new second generation antidepressant. Clin Pharmacol 4:625-636.

Lewis JA, Wu C-H, Berg H, Levine JH (1980) The genetics of lev- amisole resistance in the nematode Caenorhabditis elegans. Genetics 95:905-928.

Liu DWC, Thomas JH (1994) Regulation of a periodic motor program in C. elegans. J Neurosci 14:1953-1962.

Loer CM, Kenyon CJ (1993) Serotonin-deficient mutants and male mating behavior in the nematode Caenorhabditis elegans. J Neurosci 13:5407-5417

McDougle CJ, Goodman WK, Price LH (1993) The pharmacotherapy of obsessive-compulsive disorder. Pharmacopsychiatry Suppl 26:24 29.

McIntire SL, Jorgensen E, Horvitz HR (1993a) Genes required for GABA function in Caenorhabditis elegans. Nature 364:334-337.

McIntire SL, Jorgensen E, Kaplan J, Horvitz HR (1993b) The GABAergic nervous system of Caenorhabditis elegans. Nature 364:337341.

Mylecharane EJ (1989) The classification of 5-hydroxytryptamine receptors. Clin Exp Pharmacol Physiol 16:517-522.

Nash DT (1990) Alpha-adrenergic blockers: mechanism of action, blood pressure control, and effects of lipoprotein metabolism. Clin Cardiol 13:764-772.

Rand JB, Russell RL (1984) Choline acetyltransferase-deficient mutants of the nematode Caenorhabditis elegans. Genetics 106:227248.

Richardson BP, Engel G, Donatsch P, Stadler PA (1985) Identification of serotonin M-receptor subtypes and their specific blockade by a new class of drugs. Nature 316:126-131.

Salser SJ, Locr CM, Kenyon CJ (1993) Multiple HOM-C gene interactions specify cell fates in the nematode central nervous system. Genes Dev 7:1714-1724.

Schafer W, Kenyon CJ (1995) A calcium-channel homologue required for adaptation to dopamine and serotonin in Caenorhabditis elegans. Nature 375:73-78.

Seeman P (1987) Dopamine receptors and the dopamine hypothesis of schizophrenia. Synapse 1:133-152.

Ségalat L, Elkes DA, Kaplan J (1995) Modulation of serotonin-controlled behaviors by $G_{0}$ in Caenorhabditis elegans. Science 267: 1648-1651.

Smialowski A (1991) Dopamine $\mathrm{D}_{2}$ receptor blocking effect of imipramine in the rat hippocampus. Pharmacol Biochem Behav 39:105108.

Stockbrugger RW (1989) Antimuscarinic drugs. Methods Find Exp Clin Pharmacol Suppl 1:79-86.

Sulston J, Horvitz HR (1977) Post-embryonic cell lineages of the nematode, Caenorhabditis elegans. Dev Biol 56:110-156.

Sulston J, Dew M, Brenner S (1975) Dopaminergic neurons in the nematode Caenorhabditis elegans. J Comp Neurol 163:215-226.

Sunahara RK, Seeman P, Van Tol HHM, Niznik HB (1993) Dopamine receptors and antipsychotic drug response. Br J Psychiatry Suppl 22: $31-38$.

Thomas JH (1990) Genetic analysis of defecation in Caenorhabditis elegans. Genetics 124:855-872.

Trent C, Tsung N, Horvitz HR (1983) Egg-laying defective mutants of the nematode Caenorhabditis elegans. Genetics 104:619-647.

Waterston (1988) Muscle. In: The nematode Caenorhabditis elegans (Wood WB, cd), pp 296-304. Cold Spring Harbor, NY: Cold Spring Harbor Laboratory.

White J, Southgate E, Thomson N, Brenner S (1976) The structure of the ventral nerve cord of Caenorhabditis elegans. Philos Trans R Soc Lond [Biol] 275:327-348.

White J, Southgate E, Thomson JN, Brenner S (1986) The structure of the nervous system of the nematode Caenorhabditis elegans. Philos Trans R Soc Lond [Biol] 314:1-340. 